\title{
Dramatic response in the dependency to transfusion after low doses of lenalidomide treatment in a $5 q$-syndrome patient: a case report
}

\author{
Mehmet Hilmi Dogu, Ismail Sari, Sibel Hacioglu, Ali Keskin \\ Department of Hematology, Pamukkale University Faculty of Medicine, Denizli, Turkey
}

\begin{abstract}
$5 q$-syndrome is a special subgroup of myelodysplastic syndrome in terms of follow-up and treatment. Lenalidomide is an immunomodulatory drug that is frequently used in the treatment of multiple myeloma. Some clinical studies have shown that lenalidomide treatment is effective in $5 q$ syndrome and significantly decreases the transfusion dependency in these patients. In this paper, we would like to share a dramatic response of lowered transfusion dependency after treatment with low-dose lenalidomide in a patient who received myelodysplastic syndrome diagnosis and isolated $5 q$ anomaly in our clinic.
\end{abstract}

Key words: del(5q); Lenalidomide; myelodysplastic syndrome.

M yelodysplastic syndrome (MDS) is a progressive heterogeneous bone marrow deficiency that is characterized by variable degrees of leukopenia and anemia which can transform into acute leukemia. Besides, dysplastic changes and ineffective erythropoiesis during the maturation phase of bone marrow progenitor cells may be observed [1]. Cytogenetic anomalies are used as a criteria to determine prognosis of myelodysplastic syndrome [2, 3 ]. "5q syndrome" is a subgroup of cytogenetically isolated $5 \mathrm{q}$ anomalies that are not accompanied with a blast increase in the bone marrow, while it manifests typical dismegakaryopoietic symptoms, thrombocytosis and severe anemia $[4,5]$. In clinical studies it has been shown that treatment with lenalidomide which is an immunomodulatory drug and frequently used in multiple myeloma, is effective in 5q-syndrome significantly decreasing transfusion dependency in these patients [6].

In this paper, we would like to share dramatic response of lowered transfusion dependency after treatment with low-dose lenalidomide in a patient who was diagnosed in our clinic as myelodysplastic syndrome with isolated $5 \mathrm{q}$ anomaly. 


\section{CASE REPORT}

A 78-year-old woman presented with weakness, fatigue and hemoglobin of $8.3 \mathrm{~g} / \mathrm{dL}$, to another clinic in September, 2009, and she was given erythrocyte suspension replacement. She had regression in her existing complaints with blood replacement therapy, but after one month, same complaints reappeared with a low hemoglobin value and she was referred for further investigation to the outpatient clinic of hematology of our university faculty of medicine. Her hematologic parameters ar that time were as follows: white blood cell count of 6390/ $\mathrm{mm}^{3}$, neutrophils $3785 / \mathrm{mm}^{3}$, hemoglobin $8.1 \mathrm{~g} /$ $\mathrm{dL}$, mean corpuscular volume (MCV) $95 \mathrm{fL}$, and platelets $211.000 / \mathrm{mm} 3$. With the provisional diagnosis of myelodysplastic syndrome due to an isolated anemia unrelated to nutritional status, bone marrow aspiration biopsy was performed. Her bone marrow aspiration showed normal cellularity; and biopsy revealed increase in the number of megakaryocytes, signs of dismegakaryopoiesis, minimal dysplasia in erythroid series, and normal morphology in myeloid series. Upon conventional cytogenetical studies she was diagnosed with $5 \mathrm{q}$-syndrome. She had given erythrocyte suspension and scheduled for follow-up. She had been lost-to-follow up for approximately a year and during that time she had received a total of 4 units of erythrocyte suspension, and erythropoietin treatment was started. However, erythropoietin treatment discontinued because she did not respond to the maximum dose of $10.000 \mathrm{IU}$ three times a week. She did not attend

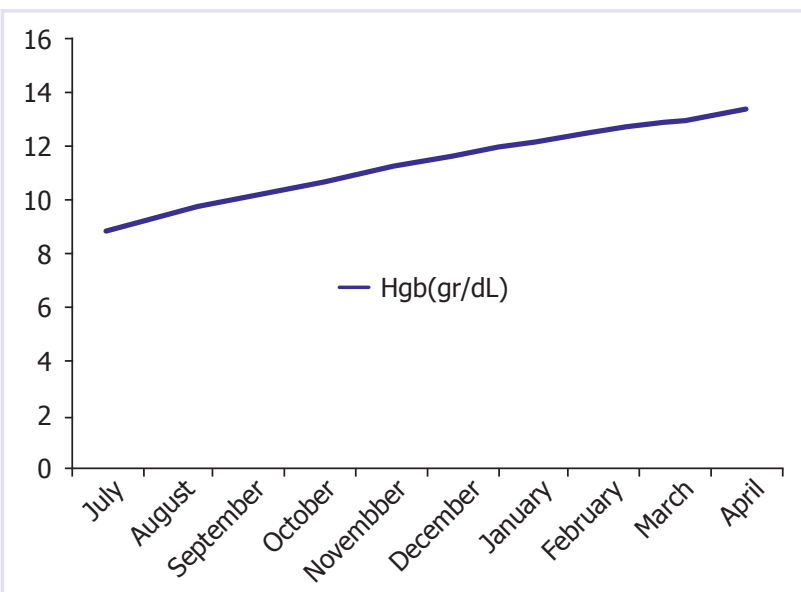

FIGURE 1. Hemoglobin monitoring after lenalidomide use. to her follow-up visits regularly and in the mean time she had transfusions monthly at another clinic. Since her transfusion dependency increased, she was considered for lenalidomide treatment in April, 2013. Lenalidomide at daily doses of $10 \mathrm{mg}$ was started in May, 2013. After 10 days of treatment, her liver enzymes increased more than 3 times of normal values and she had thrombocytopenia (platelet count: $38.000 / \mathrm{mm}^{3}$ ) Then her treatment was postponed for two weeks She restarted lenalidomide treatment at daily doses of $5 \mathrm{mg}$ after liver enzymes and platelet counts returned to normal. During further follow-up, increase in liver enzymes and severe thrombocytopenia were not detected; her hemoglobin value increased and transfusion dependency was not observed (Figure 1).

\section{DISCUSSION}

In myelodysplastic syndrome, interstitial deletion in the long arm of chromosome 5 is a common cytogenetical abnormality seen in $16-28 \%$ of the patients. Isolated 5-q syndrome is a subgroup with different clinical and pathological characteristics. It is characterized by hypoproliferative anemia and normal megakaryocytes with hypolobated nuclei or increased dysplastic megakaryocytes in bone marrow $[7,8]$. Anemia is observed with normal or increased number of thrombocytes in peripheral blood. Most of the patients are transfusion-dependent because endogen erythropoietin production is usually increased [7]. One of the major problems during the progression of the disease in transfusion-dependent MDS patients is the iron overload secondary to transfusion and the dependency for chelation therapy to treat iron overload. The immunomodulatory drug lenalidomide that has additional benefits in the regulation of erythropoiesis, inhibition of angiogenesis, and reorganization of erythroid production, targets the MDS clone directly $[9,10]$. This syndrome is rarely seen; therefore, there is not enough data about isolated $5 \mathrm{q}$-syndrome as well as lenalidomide therapy in our country. Isolated $5 \mathrm{q}$ syndrome presents with normal or increased thrombocyte counts in peripheral blood and anemia with frequent transfusion replacement dependency. In clinical studies, it has been shown that lenalidomide therapy decreases transfusion dependency [11]. Lenalidomide provided long term blood transfusion 
independency and erythroid response in patients with low - risk del (5q) and without $\operatorname{del}(5 q)$ [12]. In a phase II study of low-risk del(5q) patients; after 24 weeks, evaluation of erythrocyte response showed that $67 \%$ of the patients with $5 \mathrm{q}$ deletion who were treated with lenalidomide became transfusion independent [13]. In low- risk $5 \mathrm{q}$ deletion MDS patients, daily doses of $10 \mathrm{mg}$ for 21 days are used, and repeated with 28 day-intervals that can be modified if needed. In order to evaluate the response, treatment should be continued at least for 4 months [13, 14]. Lenalidomide treatment has a tolerable adverse event profile, besides decreasing transfusion dependency. Adverse events can be easily overcome with dose modifications. In clinical studies, thrombocytopenia and leukopenia are frequently observed but these adverse reactions usually appear during the first 8 weeks of treatment [15]. Therefore, weekly clinical follow-up at the beginning of the therapy is recommended. Less often adverse events of fatigue, rash and diarrhea can be noted [16].

In conclusion, in isolated $5 \mathrm{q}$-syndrome which is a MDS subgroup and characterized by transfusion dependency; lenalidomide can decrease transfusion dependency with a tolerable adverse event profile that can be overcome with dose modifications. Therefore lenalidomide can be considered as a treatment option. Assessment of all prevalent cases in our country will be helpful to reveal the efficacy and adverse event profile of lenalidomide.

Conflict of Interest: No conflict of interest was declared by the authors.

Financial Disclosure: The authors declared that this study has received no financial support.

\section{REFERENCES}

1. Tefferi A, Vardiman JW. Myelodysplastic syndromes. N Engl J Med 2009;361:1872-85. CrossRef

2. Greenberg P, Cox C, LeBeau MM, Fenaux P, Morel P, Sanz G, et al. International scoring system for evaluating prognosis in myelodysplastic syndromes. Blood 1997;89:2079-88.

3. Greenberg PL, Tuechler H, Schanz J, Sanz G, Garcia-Manero
G, Solé F, et al. Revised international prognostic scoring system for myelodysplastic syndromes. Blood 2012;120:2454-65. CrossRef

4. Giagounidis AA, Germing U, Wainscoat JS, Boultwood J, Aul C. The 5q- syndrome. Hematology 2004;9:271-7. CrossRef

5. Germing U, Lauseker M, Hildebrandt B, Symeonidis A, Cermak J, Fenaux P, et al. Survival, prognostic factors and rates of leukemic transformation in 381 untreated patients with MDS and $\operatorname{del}(5 q)$ : a multicenter study. Leukemia 2012;26:1286-92. CrossRef

6. Fenaux P, Giagounidis A, Selleslag D, et al. A randomized phase 3 study of lenalidomide versus placebo in RBC transfusion dependent patients with Low-/Intermediate-1-risk myelodysplastic syndromes with del 5q. Blood 2011;118:3765-76. CrossRef

7. Giagounidis AA, Germing U, Haase S, Hildebrandt B, Schlegelberger B, Schoch C, et al. Clinical, morphological, cytogenetic, and prognostic features of patients with myelodysplastic syndromes and $\operatorname{del}(5 q)$ including band q31. Leukemia 2004;18:113-9. CrossRef

8. Bernasconi P, Klersy C, Boni M, Cavigliano PM, Calatroni S, Giardini I, et al. Incidence and prognostic significance of karyotype abnormalities in de novo primary myelodysplastic syndromes: a study on 331 patients from a single institution. Leukemia 2005;19:1424-31. CrossRef

9. Eisenmann KM, Dykema KJ, Matheson SF, Kent NF, DeWard $\mathrm{AD}$, West RA, et al. 5q- myelodysplastic syndromes: chromosome $5 \mathrm{q}$ genes direct a tumor-suppression network sensing actin dynamics. Oncogene 2009;28:3429-41. CrossRef

10. Kotla V, Goel S, Nischal S, Heuck C, Vivek K, Das B, et al. Mechanism of action of lenalidomide in hematological malignancies. J Hematol Oncol 2009;2:36. CrossRef

11. Giagounidis AA, Germing U, Aul C. Biological and prognostic significance of chromosome $5 \mathrm{q}$ deletions in myeloid malignancies. Clin Cancer Res 2006;12:5-10. CrossRef

12. Kurtin SE, List AF. Durable long-term responses in patients with myelodysplastic syndromes treated with lenalidomide. Clin Lymphoma Myeloma 2009;9:E10-3. CrossRef

13. List A, Dewald G, Bennett J, Giagounidis A, Raza A, Feldman E, et al. Lenalidomide in the myelodysplastic syndrome with chromosome 5q deletion. N Engl J Med 2006;355:1456-65. CrossRef

14. Mallo M, Del Rey M, Ibáñez M, Calasanz MJ, Arenillas L, Larráyoz $\mathrm{MJ}$, et al. Response to lenalidomide in myelodysplastic syndromes with $\operatorname{del}(5 \mathrm{q})$ : influence of cytogenetics and mutations. $\mathrm{Br}$ J Haematol 2013;162:74-86. CrossRef

15. List A, Kurtin S, Roe DJ, Buresh A, Mahadevan D, Fuchs D, et al. Efficacy of lenalidomide in myelodysplastic syndromes. $\mathrm{N}$ Engl J Med 2005;352:549-57. CrossRef

16. List AF, Baker AF, Green S, Bellamy W. Lenalidomide: targeted anemia therapy for myelodysplastic syndromes. Cancer Control 2006;13 Suppl:4-11. 